\title{
Depression and suicidality among Egyptian renal transplant recipients
}

\author{
Naglaa El-Mahalawy, Ahmed Saad, Samah Rabei, Hanan Elrassas*, Ahmed Abdelgawad, Marwa Elmissiry and
} Rami Aly

\begin{abstract}
Background: High rates of depression and suicidality risk have been reported after renal transplantation. The study aims to estimate the prevalence of depressive disorders and suicidality risk among Egyptian renal transplant recipients and their demographic and clinical correlates.

Results: The prevalence of depressive disorders among renal transplant recipients was (32.2\%). Major depression (16.5\%), adjustment disorder depressive type (9.13\%) while dysthymic disorder occurred in (6.5\%). Suicidality risk was present among $31.3 \%$ of the sample. Hopelessness was the commonest depressive symptoms within the depressed patients. There was a statistically significant association of depression and risk of suicidality, with age, educational attainment, employment, and the presence of side effects of medication. However, there was no significant correlation between depression or suicidality, with marital status, type of donor, duration of dialysis, and associated other medical illnesses. Despite there was no relation between gender and severity of depression, yet male recipients showed more pronounced suicidal risk.
\end{abstract}

Conclusions: The prevalence of depression and suicidality is quite high among post renal transplantation recipients (PRTRs). Early psychiatric evaluation and intervention together with regular long term follow-up from the multidisciplinary team are necessary for recipients after renal transplant operation.

Keywords: Depression, Renal transplantation, Suicidality, Renal transplant recipients

\section{Background}

Renal transplantation (RT) could be the treatment of choice for some patients with end-stage renal disease (ESRD). It offers several advantages in terms of improved clinical outcomes and quality of life (QoL) compared to dialysis modalities $[1,2]$. Despite the benefits of receiving a donor kidney, there is high evidence of developing depression in those who have been transplanted [3].

Depression may affect up to $25 \%$ of patients who underwent RT. Furthermore, it is associated with poor outcome following RT and related to poor postoperative patients' compliance to immunosuppressive drugs [1]. Thus, early detection and treatment of depression is important to improve patients' adherence to treatment,

* Correspondence: Hanan_elrassas@yahoo.com

Okasha Institute of Psychiatry, Faculty of Medicine, Ain Shams University, 168 Elnozha St, Saint Fatima, Heliopolis, Cairo, Egypt their QoL, and outcomes in transplant recipients [4]. Similarly, suicidal ideation and hopelessness are important symptomatology in transplant recipients in association with depression [5].

This research is the second part of an investigation of psychiatric morbidity among renal transplant recipients [6].

To our knowledge, no previous studies reported the prevalence of depression and suicidality among RT patients in Egypt. Thus, the aim of the current study is to estimate the prevalence of depression and suicidality among renal transplant recipients and to find the possible demographic and clinical correlates.

\section{Methods \\ Participants}

We conducted this cross-sectional observational study in two general hospitals in Cairo along 1 year. A stratified

\section{Springer Open}

(c) The Author(s). 2020 Open Access This article is licensed under a Creative Commons Attribution 4.0 International License, which permits use, sharing, adaptation, distribution and reproduction in any medium or format, as long as you give appropriate credit to the original author(s) and the source, provide a link to the Creative Commons licence, and indicate if changes were made. The images or other third party material in this article are included in the article's Creative Commons licence, unless indicated otherwise in a credit line to the material. If material is not included in the article's Creative Commons licence and your intended use is not permitted by statutory regulation or exceeds the permitted use, you will need to obtain permission directly from the copyright holder. To view a copy of this licence, visit http://creativecommons.org/licenses/by/4.0/. 
random sample of post renal transplant recipients (PRTRs) who came for follow-up in the renal transplantation clinic in both Ain Shams University Specialized Hospital and Naser Institute Hospital. We recruited 230 recipients that underwent renal transplant surgery. The sample size was calculated using the Epi-info program version 6 by a statistician. No inclusion or exclusion criteria were done. All participants received their implanted organs from living donors.

\section{Assessment}

We collected sociodemographic information, including age, gender, employment status, marital status, educational attainment, and social class. Most of our recipients belong to the low and middle socio-classes who attended state hospitals in which the cost of services is covered mostly by the government.

Also, we used the semi-structured questionnaire for renal transplant recipients to determine both the medical condition and the circumstances of the RT surgery among PRTRs [7].

We used the Structured Clinical Interview for DSM-IV Axis I disorder (SCID-I) [8] for the diagnoses of depression. We used the Arabic version which previously translated and validated [9]. Patients with diagnosis of depression were further assessed for severity of depression using the Beck depression inventory (BDI) [10], however we used the Arabic version by [11]. Suicidality was assessed for all the participants using the Suicide Probability Scale (SPS) [12], also we used the Arabic standardized version [13].

\section{Ethical consideration}

The study protocol was approved by the Ethical Committee Research of the Faculty of Medicine-Ain Shams University approvals from the hospital authorities were provided. An informed written consent was taken from all participants. Confidentiality was ensured and explanation of the nature of the research was ensured. Recipients were guaranteed that their participation was voluntarily, and refusal would not affect their clinical care.

\section{Statistical methods}

The collected data were analyzed using the statistical package for the social sciences [14]. Qualitative data was described using frequency and percentage. Quantitative data was described using mean and standard deviation. The following inferential statistical procedures were used; categorical data was compared using the chisquare test. Continuous variables were compared using the student " $t$ " test and statistical significance was set at $p<0.05$.

\section{Results}

The age ranged of the study groups was from 18 to 60 years old with a mean age of $37.3 \pm 7.6$ years. Seventytwo percent were males and $28 \%$ were females. The majority received a considerable year of education and (17.8\%) were illiterate; most of the PRTRs (73\%) were married, while the rest were single, divorced, or widow. A considerable percentage was employed (70\%) and about $23 \%$ were unemployed and $7 \%$ were housewives. Sixtynine percent of PRTRs got the transplant graft from nonrelative donors, whereas $31 \%$ received it from relatives.

The duration of follow-up from the time of RTS until the time of conducting this research ranged from 3 months to 18 years.

Depressive disorders were found in 74 patients (32.2\%). The commonest diagnosis is a major depressive episode (38 patients, $16.5 \%$ ), followed by adjustment disorder depressive type (21 patients, 9.2\%), and then dysthymia (15 patients, $6.5 \%$ ). Those who had no depression were 156 patients $(67.8 \%)$ (Fig. 1$)$.

The severity of depression as estimated by BDI revealed that mild depression is the commonest (12.6\%), followed by moderate depression (11.3\%). While (8.3\%) had severe depression (Fig. 2).

Risk of suicidality was detected in 72 patients (31.3\%). Mild risk was the commonest (59 patients, 25.65\%), followed by moderate risk (13 patients, $5.65 \%$ ), and there was no severe risk of suicidality (Fig. 3). The commonest depressive symptoms detected according to the SPS subscales were hopelessness (46 patients, 20\%), followed by suicidal ideation (17 patients, $7.39 \%$ ), negative selfevaluation, and hostility (each, 1.3\%) (Fig. 4).

\section{Severity of depression and suicidality in relation to socio- demographic and clinical variables}

Age was significantly associated with the severity of depression according to BDI. Our data revealed that severe depression is significantly highest (31.4\%) in the youngest age groups (18-30 years) followed by the eldest group (50-60 years) (26.4\%). Moderate depression was more pronounced in the age group 30-40 (38\%) and the age group 40-50 (27.6\%) $P<0.01$. No severe risk of suicidality among our PRTRs as assessed by SPS, however, moderate suicidal risk was more pronounced in the age group (40-50 years) and mild form is more prevalent in the age group (50-60 years) (Tables 1 and 2).

Despite that, Table 1 shows non statistically significant difference between male and females recipients in relation to depression severity, yet moderate suicidality risk was extremely higher in male patients 76 (92\%) (Tables 1 and 2). Severe depression and moderate risk of suicidality were by far more significantly pronounced in the educated patients who received 12 years or more of education $P<0.01$. 




Fig. 1 Rate and type of depression (depression $=32.2 \%$, no depression 67.8\%)

Patients without a job had more significant higher level of moderate depression (69.23\%) while unskilled and semiprofessionals showed a higher significant level of severe depression (52.63\% and $47.36 \%)$ respectively (Table 1). Moderate suicidal risk was detected more in the semiprofessionals (76.9\%), whereas mild risk prevailed among unskilled (30.5\%) (Tables 1 and 2). There was no significant relationship between severity of depression or risk of suicidality with marital status. Severity depression and risk of suicidality were more common among patients suffering from medication side effects compared to those who did not record side effects. Furthermore, there were no statistically significant differences as regards, types of donors, presence of comorbid medical disease, and duration of hemodialysis prior to renal transplant or duration of the transplant graft.

\section{Discussion}

The International Federation of Renal Registries [15] estimated the prevalence of renal failure in Egypt according to its report in 2003 between 9-14.5\%. Although the number of patients increases by time and the transplant activity program increased, yet still the rate of RTs in Egypt is slower in comparison to the Western world [16]. This may be due to the restriction of non-relative donors to guard against illegal organ commerce [17]. Living donation is the most prevalent type of donation, while the deceased donation is not well established in the Middle East probably due to religious issues [18].

A plethora of studies stated that the renal transplant recipients are at risk to develop psychiatric disorders specifically depression $[19,20]$. Which may contribute to unfavorable outcomes, poor adherence to treatment plans, and low employment rate after RTs [3, 21, 22]. Despite the high rate of depression and suicidality after RTs, this field is still an unstudied area in Egypt. Thus, we aimed at measuring the rates of depression and suicidality and their sociodemographic and clinical correlates among Egyptian post renal transplant recipients.

In this study, $32.2 \%$ of the participants were diagnosed to have one of the depressive disorders according to the criteria of DSM-IV diagnostic system. Major depressive disorder was found in $16.5 \%$ of PRTR, also depressive symptoms as a part of adjustment disorder depressive type and dysthymic disorder were found in $9.13 \%$ and $8.23 \%$ respectively; these results suggesting that depressive symptoms were common among PRTR in Egypt. There was a wide range of variation in estimating the prevalence of depression among different countries. The lower rates (11.8\%) were recorded in Panama [21], (22\%) in Canada [3], (25.6\%) in Sudan [23], and (25\%) in Turkey [24]. On the other hand, higher rates (59.2\%) were estimated in China [22], (75\%) in Iran [25], and in Japan (41.4\%) [26].

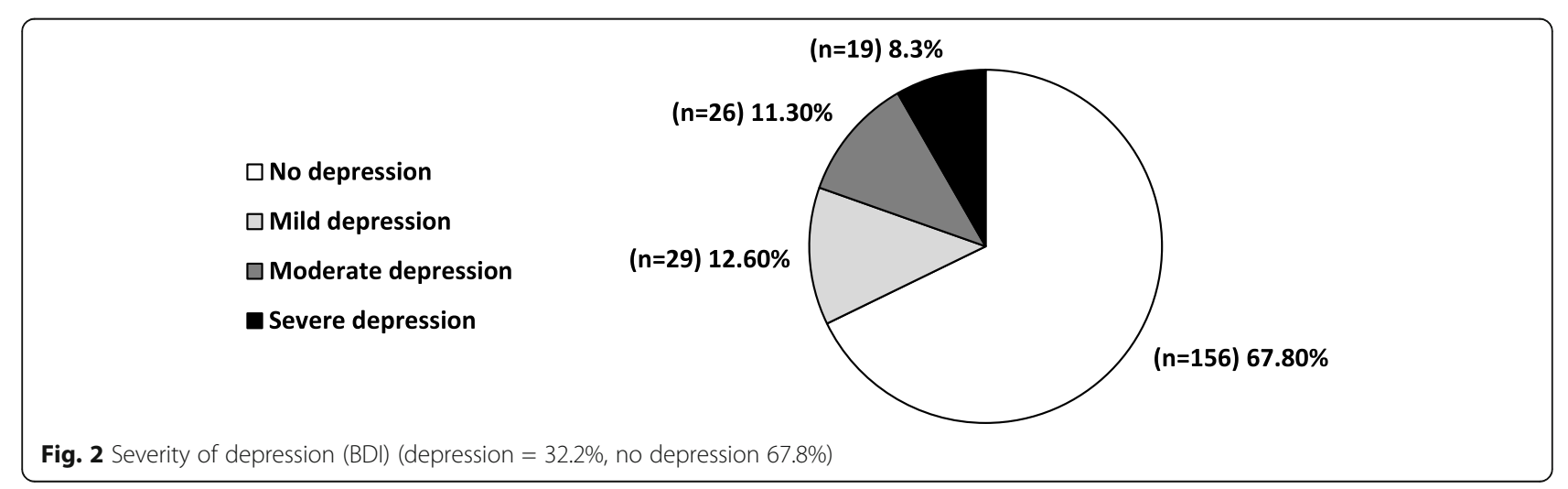




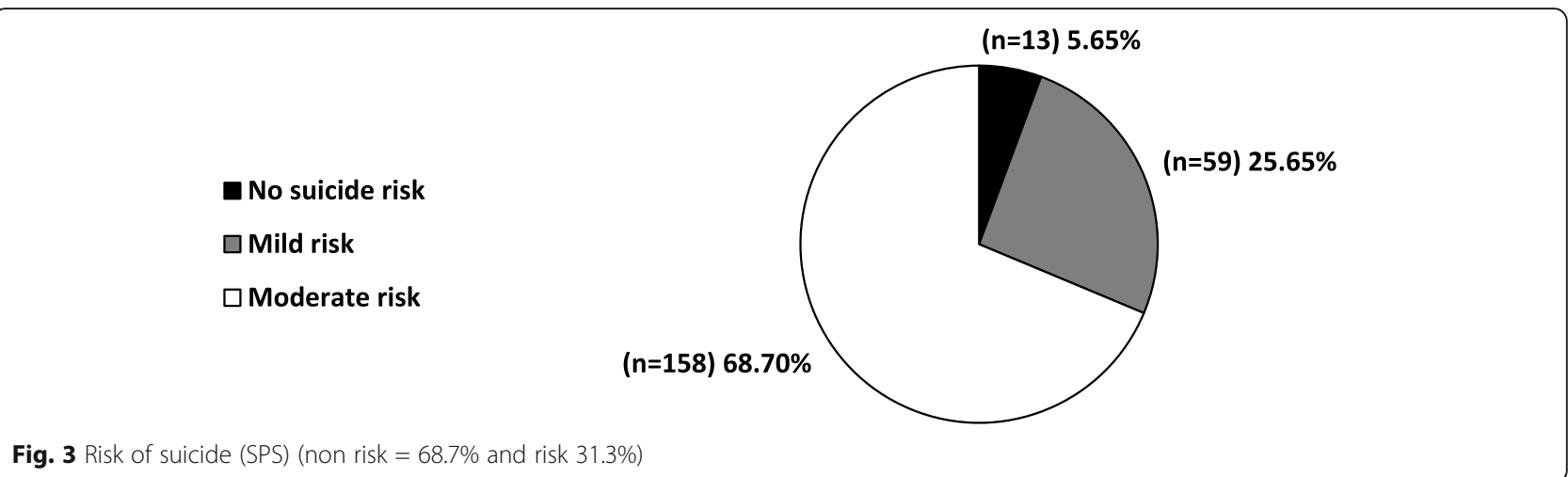

The great variation of the prevalence of depression in different countries may be related to the use of different tools of screening and assessment. We use SCID-I for diagnosis of depression, similarly in Panama, the investigators used the Mini International Neuropsychiatric Interview (MINI) [21, 27].

While the use of CES-D = score $>18$ and SCL-9 $>25$ revealed that $22 \%$ and $31 \%$ respectively rate of depression among renal transplant recipients [28, 29]. Other studies used self-assessment tools as BDI which led to estimates ranging from 13 to $39 \%[27,30]$.

Other variables that may be related to a wide variation of the prevalence of depression in different countries may be attributable to different sampling methods, presence of selection bias, and cultural differences affecting the patient perception of depression.

According to Chilcot and his coworkers [1], who stated that severity of depression is the most important issue in recognizing depression in the context of transplantation, we decided to use the Beck Depression Inventory to unravel the severity of depressive symptoms among our PRTRs. Findings revealed that $12.6 \%$ had mild and $11.3 \%$ had moderate depression while only $8.53 \%$ had severe depression. We are in concordance with the previous studies which recorded that the majority of PRTRs had mild to moderate depression [22, 23]. Moreover, moderate and severe depression in renal transplant were estimated by other investigators [24, 31].

There is no substantial information about suicidality after renal transplantation as this area is poorly studied. Kurella and his colleagues [32] stated that suicidal behavior is higher in PRTPs compared to the rates of the general population. In our study using SPS, the risk of suicide was detected in (72 patients, 31.3\%). Mild risk was the commonest (59 patients, $25.65 \%$ ), followed by moderate risk (13 patients, $5.65 \%$ ) and there was no severe risk of suicide. The comparison of our findings with other studies was hampered by the lack of previous investigations highlighting this area.

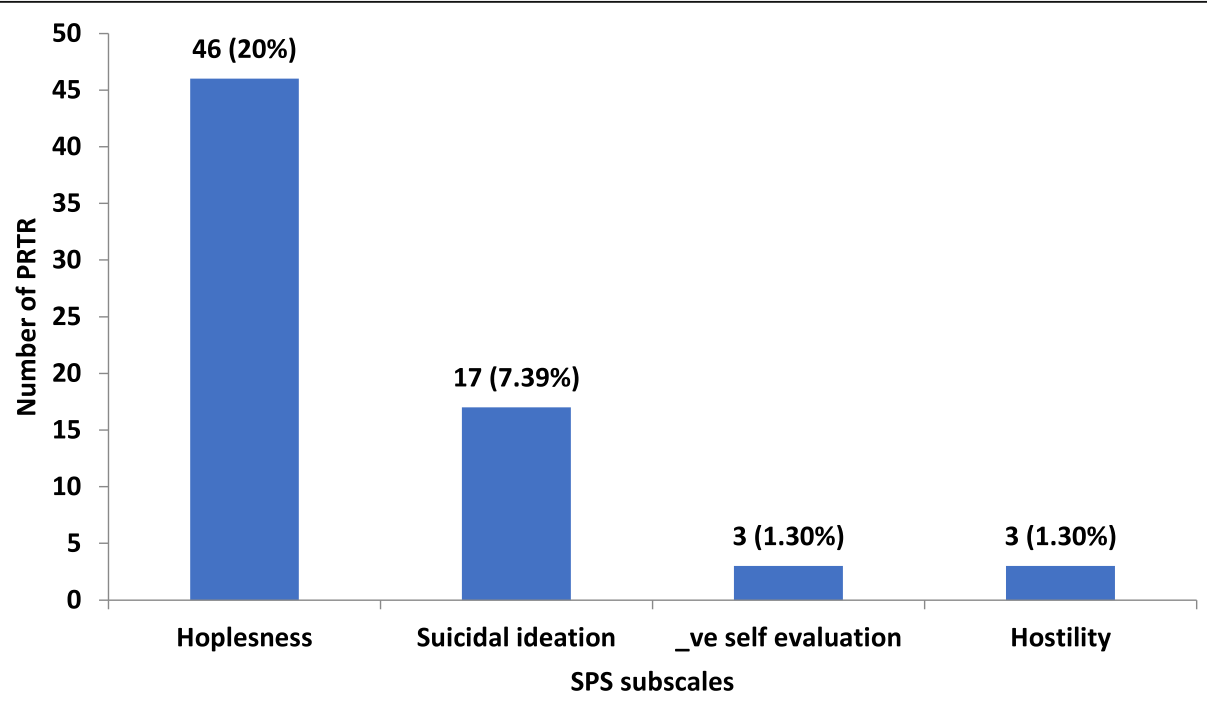

Fig. 4 Depressive symptoms (SPS-subscales) 
Table 1 Severity of depression in relation to sociodemographic and clinical variables in PRTRs

\begin{tabular}{|c|c|c|c|c|c|c|}
\hline Variables & Severe $(\boldsymbol{n}=19)$ & Moderate $(\boldsymbol{n}=26)$ & Mild $(\boldsymbol{n}=29)$ & No depression $(\boldsymbol{n}=156)$ & $x 2$ & $\boldsymbol{P}$ value \\
\hline \multicolumn{7}{|l|}{ Age } \\
\hline $18-30$ years & $6(31.6 \%)$ & $14(53.9 \%)$ & $6(20.6 \%)$ & $42(26.9 \%)$ & \multirow[t]{4}{*}{18} & \multirow[t]{4}{*}{$<0.01$} \\
\hline$>30-40$ years & $4(21 \%)$ & $3(11.5 \%)$ & $11(38 \%)$ & $53(34 \%)$ & & \\
\hline$>40-50$ years & $4(21 \%)$ & $5(19.2 \%)$ & $8(27.6 \%)$ & $44(28.2 \%)$ & & \\
\hline$>50-60$ years & $5(26.4 \%)$ & $4(15.4 \%)$ & $4(13.8 \%)$ & 17 (10.9\%) & & \\
\hline \multicolumn{7}{|l|}{ Sex } \\
\hline Males & $11(57.9 \%)$ & $20(76.9 \%)$ & $20(68.9)$ & 114 (73\%) & & \multirow[t]{2}{*}{$>0.05$} \\
\hline Females & $8(42.1 \%)$ & $6(23.1 \%)$ & 9 (31.1\%) & $42(27 \%)$ & & \\
\hline \multicolumn{7}{|l|}{ Education } \\
\hline Illiterate & $2(10.52 \%)$ & $0(0 \%)$ & $2(6.89 \%)$ & $37(23.71 \%)$ & \multirow[t]{6}{*}{6.3} & \multirow[t]{6}{*}{$<0.01$} \\
\hline 6 years & $5(26.31 \%)$ & $4(15.38 \%)$ & $0(0 \%)$ & $16(10.25 \%)$ & & \\
\hline 9 years & $0(0 \%)$ & $6(23.07 \%)$ & $5(17.24 \%)$ & $33(21.15 \%)$ & & \\
\hline 12 years & $8(42.10 \%)$ & $5(19.23 \%)$ & $11(37.93 \%)$ & $30(19.23 \%)$ & & \\
\hline 14 years & $4(21.05 \%)$ & $4(15.38 \%)$ & $3(10.34 \%)$ & $9(5.76 \%)$ & & \\
\hline$>14$ years & $0(0 \%)$ & 7 (26.92\%) & $8(27.58 \%)$ & 31 (19.87\%) & & \\
\hline \multicolumn{7}{|l|}{ Occupational level } \\
\hline Unemployed & $0(0 \%)$ & $18(69.23 \%)$ & $6(20.68 \%)$ & $29(18.58 \%)$ & \multirow[t]{6}{*}{6.5} & \multirow[t]{6}{*}{$<0.05$} \\
\hline Unskilled & $10(52.63 \%)$ & $2(7.69 \%)$ & $2(6.89 \%)$ & $44(28.20 \%)$ & & \\
\hline Semi skilled & $0(0 \%)$ & $2(7.69 \%)$ & 7 (24.13\%) & 17 (10.89\%) & & \\
\hline Semi professional & 9 (47.36\%) & $2(7.69 \%)$ & 7 (24.13\%) & $32(20.51 \%)$ & & \\
\hline Professional & $0(0 \%)$ & $0(0 \%)$ & 7 (24.13\%) & $18(11.53 \%)$ & & \\
\hline House wife's & $0(0 \%)$ & $2(7.69 \%)$ & $0(0 \%)$ & $16(10.25 \%)$ & & \\
\hline \multicolumn{7}{|l|}{ Marital status } \\
\hline Single & $0(0 \%)$ & $4(15.38 \%)$ & $9(31.03 \%)$ & $41(26.28 \%)$ & \multirow[t]{4}{*}{3} & \multirow[t]{4}{*}{$>0.05$} \\
\hline Married & 19 (100\%) & $18(69.23 \%)$ & $19(65.51 \%)$ & 112 (71.79\%) & & \\
\hline Divorced & $0(0 \%)$ & 4 (15.38\%) & $1(3.44 \%)$ & $0(0 \%)$ & & \\
\hline Widow & $0(0 \%)$ & $0(0 \%)$ & $0(0 \%)$ & $3(1.92 \%)$ & & \\
\hline \multicolumn{7}{|l|}{ Type of donors } \\
\hline Relative & $12(63.15 \%)$ & $4(15.38 \%)$ & $10(34.48 \%)$ & $45(28.84 \%)$ & \multirow[t]{2}{*}{3.8} & \multirow[t]{2}{*}{$>0.05 \mathrm{NS}$} \\
\hline Non relative & 7 (36.84\%) & 22 (84.61\%) & $19(65.51 \%)$ & 111 (71.15\%) & & \\
\hline \multicolumn{7}{|l|}{ Medical disease } \\
\hline Present & $5(26.31 \%)$ & $5(19.23 \%)$ & $16(55.17 \%)$ & $61(39.10 \%)$ & \multirow[t]{2}{*}{4.4} & \multirow[t]{2}{*}{$>0.05 \mathrm{NS}$} \\
\hline Absent & $14(73.68 \%)$ & $21(80.76 \%)$ & $13(44.82 \%)$ & $95(60.89 \%)$ & & \\
\hline \multicolumn{7}{|c|}{ Duration of hemodialysis } \\
\hline$<1$ year & $0(0 \%)$ & $11(42.30 \%)$ & $23(79.31 \%)$ & $66(42.30 \%)$ & \multirow[t]{3}{*}{1.9} & \multirow[t]{3}{*}{$>0.05$} \\
\hline $1-4$ years & 19 (100\%) & $15(57.69 \%)$ & $2(6.89 \%)$ & $71(45.51 \%)$ & & \\
\hline 4-7 years & $0(0 \%)$ & $0(0 \%)$ & $4(13.79 \%)$ & 19 (12.17\%) & & \\
\hline Side effects of drugs & ed after & & & & & \\
\hline Side effects & 19 (100\%) & 12 (46.15\%) & 21 (72.41\%) & $88(56.41 \%)$ & 8.8 & $<0.01$ \\
\hline No Side effects & $0(0 \%)$ & 14 (53.84\%) & $8(27.58 \%)$ & $68(43.58 \%)$ & & \\
\hline Duration of graft & & & & & & \\
\hline 1 year & $8(42.10 \%)$ & $2(7.69 \%)$ & $10(34.48 \%)$ & $21(13.46 \%)$ & 2.8 & $>0.05$ \\
\hline $1-4$ years & $2(10.52 \%)$ & $13(50 \%)$ & $2(6.89 \%)$ & 77 (49.35\%) & & \\
\hline 4-8 years & 5 (26.31\%) & 4 (15.38\%) & $14(48.27 \%)$ & $48(30.76 \%)$ & & \\
\hline 8-17 years & $4(21.05 \%)$ & 7 (26.92\%) & $3(10.34 \%)$ & $10(6.41 \%)$ & & \\
\hline
\end{tabular}


Table 2 Severity of suicidality risk in relation to sociodemographic and clinical variables in PRTRs

\begin{tabular}{|c|c|c|c|c|c|}
\hline Variable & Moderate $(\boldsymbol{n}=13)$ & Mild $(\boldsymbol{n}=59)$ & No $(\boldsymbol{n}=158)$ & $x 2$ & $\boldsymbol{P}$ value \\
\hline \multicolumn{6}{|l|}{ Suicidality } \\
\hline \multicolumn{6}{|l|}{ Age } \\
\hline $18-30$ years & $1(7.69 \%)$ & $17(25 \%)$ & $50(73.5 \%)$ & 23 & $<0.01$ \\
\hline$>30-40$ years & $3(23.07 \%)$ & 12 (16.9\%) & $56(78.8 \%)$ & & \\
\hline$>40-50$ years & $9(69.23 \%)$ & $18(29.5 \%)$ & 34 (55.7\%) & & \\
\hline$>50-60$ years & $0(0 \%)$ & $12(40 \%)$ & $18(60 \%)$ & & \\
\hline \multicolumn{6}{|l|}{ Sex } \\
\hline Males & 10 (76.92\%) & 42 (71.18\%) & $113(71.51 \%)$ & & $<0.05$ \\
\hline Females & $3(23.07)$ & 17 (28.81\%) & $45(28.48 \%)$ & & \\
\hline \multicolumn{6}{|l|}{ Education } \\
\hline Illiterate & $0(0 \%)$ & $6(10.16 \%)$ & $35(22.15 \%)$ & 5.9 & $<0.01$ \\
\hline 6 years & $0(0 \%)$ & 8 (13.55\%) & $17(10.75 \%)$ & & \\
\hline 9 years & $0(0 \%)$ & 9 (15.25\%) & $35(22.15 \%)$ & & \\
\hline 12 years & $13(100 \%)$ & $16(27.11 \%)$ & 35 (22.15\%) & & \\
\hline 14 years & $0(0 \%)$ & $4(6.77 \%)$ & $16(10.12 \%)$ & & \\
\hline$>14$ years & $0(0 \%)$ & $16(27.11 \%)$ & $30(18.98 \%)$ & & \\
\hline \multicolumn{6}{|l|}{ Occupational level } \\
\hline Unemployed & $0(0 \%)$ & 11 (18.64\%) & $42(26.58 \%)$ & 7.8 & $<0.05$ \\
\hline Unskilled & $0(0 \%)$ & $18(30.50 \%)$ & $40(25.31 \%)$ & & \\
\hline Semi skilled & $0(0 \%)$ & $14(23.72 \%)$ & 12 (7.59\%) & & \\
\hline Semi professional & 10 (76.92\%) & 9 (12.25\%) & 31 (19.62\%) & & \\
\hline Professional & $3(23.07 \%)$ & $4(6.77 \%)$ & $18(11.39 \%)$ & & \\
\hline House wife's & $0(0 \%)$ & $3(5.08 \%)$ & 15 (9.49\%) & & \\
\hline \multicolumn{6}{|l|}{ Marital status } \\
\hline Single & $2(15.38 \%)$ & 11 (18.64\%) & 41 (25.94\%) & 1 & $>0.05$ \\
\hline Married & 11 (84.61\%) & $48(81.35 \%)$ & 109 (75.31\%) & & \\
\hline Divorced & $0(0 \%)$ & $0(0 \%)$ & $5(3.16 \%)$ & & \\
\hline Widow & $0(0 \%)$ & $0(0 \%)$ & $3(1.89 \%)$ & & \\
\hline \multicolumn{6}{|l|}{ Type of donors } \\
\hline Relative & 7 (53.84\%) & 11 (18.64\%) & $53(33.54 \%)$ & 3.3 & $>0.05$ \\
\hline Non relative & $6(46.15 \%)$ & $48(81.35 \%)$ & $105(66.45 \%)$ & & \\
\hline \multicolumn{6}{|l|}{ Medical disease } \\
\hline Present & $9(69.23 \%)$ & $17(28.81 \%)$ & $61(38.60 \%)$ & 3.2 & $>0.05$ \\
\hline Absent & $4(30.76 \%)$ & $42(71.18 \%)$ & 97 (61.39\%) & & \\
\hline \multicolumn{6}{|c|}{ Duration of hemodialysis } \\
\hline$<1$ year & $6(46.15 \%)$ & $26(44.06 \%)$ & $66(41.77 \%)$ & 3.5 & $>0.05$ \\
\hline $1-4$ years & 7 (53.84\%) & $29(49.15 \%)$ & $71(44.93 \%)$ & & \\
\hline 4-7 years & $0(0 \%)$ & $4(6.77 \%)$ & $19(12.02 \%)$ & & \\
\hline \multicolumn{6}{|c|}{ Side effects of drugs received after } \\
\hline Side effects & $13(100 \%)$ & 41 (69.49\%) & 8855.69 & 2.9 & $<0.01$ \\
\hline No Side effects & $0(0 \%)$ & $18(30.50 \%)$ & $72(45.56 \%)$ & & \\
\hline \multicolumn{6}{|l|}{ Duration of graft } \\
\hline 1 year & $0(0 \%)$ & $11(18.64)$ & 30 (18.98\%) & 2.9 & $>0.05$ \\
\hline $1-4$ years & 5 (38.46\%) & 21 (35.59\%) & $68(43.03 \%)$ & & \\
\hline
\end{tabular}


Table 2 Severity of suicidality risk in relation to sociodemographic and clinical variables in PRTRs (Continued)

\begin{tabular}{|c|c|c|c|c|c|}
\hline Variable & Moderate $(\boldsymbol{n}=13)$ & Mild $(\boldsymbol{n}=59)$ & No $(\boldsymbol{n}=158)$ & $x 2$ & $\boldsymbol{P}$ value \\
\hline 4-8 years & $2(15.38 \%)$ & 21 (35.59\%) & 48 (30.37\%) & & \\
\hline 8-17 years & 6 (46.15\%) & $6(10.16 \%)$ & 12 (7.59\%) & & \\
\hline
\end{tabular}

No severity risk for suicidality has been recorded

Reporting symptoms of depression according to the SPS revealed that our patients scored higher in items of hopelessness (20\%), suicidal ideation 7 (3.9\%), negative selfevaluation (1.3\%), and hostility (1.3\%). In his study and Andrade and his coworkers [4] in Brazil 2015, used the Beck Hopelessness Scale (BHS) they found that $89 \%$ had minimal hopelessness symptoms, $10 \%$ had moderate, and only $1 \%$ have severe symptoms. Differences in these results may be due to the use of different tools of measurement.

Depression after renal transplantation is by multiple complex and overlapping factors. Thus, we analyzed the sociodemographic and clinical variables in relation to the intensity of depressive symptoms and suicidality risk. Age has previously shown to be predictive for depression in renal transplant recipients, our results are in accordance with previous studies [26, 29, 33]. The current study showed that severe depression was significantly associated with the youngest and eldest age groups while moderate depression and moderate risk of suicidality were prevalent among middle-age groups.

We assumed that depression in the youngest age group may be related to the fear of graft rejection or future complications, whereas in the eldest group may be related to lack of social support. Other reports found an insignificant relation between age and development of depression in renal transplant recipients [22, 24].

The current findings are in agreement with Arapaslan and his co-investigators [24] who found that there is an insignificant difference between males and females transplant recipients as regards the presence of depression. Moreover, we found that moderate and mild suicidality risks were higher in male patients. Our report comes primarily from males who comprised about $70 \%$ of our cases, probably this contributes to the fact that our results do not agree with previous findings which reported that women recipients have significantly higher rates of depression [34, 35]. Some investigators found that depression is more common in unmarried transplant recipients due to lack of social support [1, 34]. However; we are in agreement with other investigators who did not find any relation between marital status and developing depression among PRTRs [22].

On the contrary of the previous report which found that low educational attainment is predictive of depression in renal transplant recipients $[21,22,36]$; in the current study, we found that severe depression and moderate suicidality risk were more significantly common in educated patients. Similarly, Zarifian and his coworkers [37] concluded that depression is correlated with high educational attainment.

Education may give more chances to the patient to seek information and to know the hazards and complications of the surgery, weakened immune system, and possibility of graft rejection. Employment status is a major factor influencing the developing of depression in PRTRs. Our study showed that unemployed subjects had significant higher levels of moderated depression (69.23\%). Similarly, McGee and Thompson [38] found that depression is significantly correlated to lower occupational level $(p<0.05)$, and this finding may be linked to impaired functioning, frequent absence from work, and low productivity in patients with depression. On the other hand, semiprofessionals and unskilled patients in our study showed a high level of severe depression and moderate suicidality risk. We assumed that fear of nonreturn to work and instructions to avoid exposure to a public place or to limit working hours are the possible factors behind depression in professionals and semiskilled laborers.

Long pretransplant dialysis periods were reported by previous investigators to be associated with depression $[3,25]$. While in this current research and in other previous publications, there was no such association [22]. There is little evidence that the duration of the transplant graft survival is associated with mood changes in renal recipient. In a previous report, there were no significant differences for different duration $<5,5-10,10$ $15,>15$ years duration of graft [22].

We agreed with these findings on the contrary of Akman and his colleagues [34] who found that patients with longer functional graft had lesser depression. Psychological problems may occur in association with immunosuppressive drugs and steroids in high doses [39, 40]. Similarly, we found that depression was more common among patients who suffered from side effects of post transplant medications $(37.2 \%)$ compared to patients without side effects $(24.5 \%)(p<0.01)$.

This study was limited by its cross-sectional design, and limited recruitment from only two governmental hospitals, thus, we did not include private hospitals in which more affluent patients were presented making limitations in the generalizability of the obtained data. We did not explore some variables as past psychiatric history, coping strategies, and perceived social support. These points should be taken into consideration in future research. 
Despite that renal transplantation is the only potentially curative treatment for end-stage renal failure and it might be thought that depression would decrease after operation, yet paradoxical depression is commonly happened and is considered the commonest long term complication after RTs [40]. A wide range of diverse, psychological, biological, and social factors are interrelated and may contribute to the development of depression among those patients [21, 41].

\section{Conclusion}

The prevalence of depression and suicidality is quite high among post renal transplantation recipients (PRTRs), that was associated with age, educational attainment, employment, and the presence of side effects of medication. Our findings pointed to the need of recognizing depression and its psychosocial correlates among renal transplant recipients. Accordingly, the multidisciplinary team should integrate mental health professionals to avoid the negligence of psychiatric morbidity and its correlates which can undermine the transplant success and lead to excessive suffering of those patients.

\section{Abbreviations}

BD: Beck depression inventory; ESRD: End-stage renal disease; PRTR: Post renal transplantation recipients; Qo: Quality of life; R: Renal transplantation; SCID-1: Structured Clinical Interview for DSM-IV Axis I disorder; SPS: Suicide Probability Scale

\section{Acknowledgements}

This study could not be completed without the support of Prof. Essam Khider, Professor of Nephrology, Ain Shams University, Prof. Ahmed Saad, and Prof. Amani Haroun, Prof. Hisham Hatata Professors of Neuropsychiatry, Ain Shams University and Dr. Mostafa Bastawy for the statistical analysis.

\section{Authors' contributions}

NE: the conception, design of the work; the acquisition, analysis, interpretation of data; revised the manuscript. AS: the conception, design of the work; the acquisition, analysis, interpretation of data; revised the manuscript. SR: the acquisition, analysis, interpretation of data; drafted the manuscript; revised the manuscript. HE: the conception, design of the work; the acquisition, analysis, interpretation of data; drafted the manuscript; revised the manuscript. AA: the acquisition, analysis, interpretation of data; revised the manuscript. ME: the conception, design of the work; the acquisition, analysis, interpretation of data; revised the manuscript. RA: drafted the manuscript; revised the manuscript. All authors have read and approved the manuscript.

\section{Funding}

None

\section{Availability of data and materials}

All data generated or analyzed during this study are included in this published article

\section{Ethics approval and consent to participate}

The study was approved by the ethics committee of the Faculty of Medicine Ain Shams University, Cairo, Egypt (the reference number is not available). Consent for participation was obtained from all patients.

\section{Consent for publication}

Consent for publication was obtained.

\section{Competing interests}

None for all authors

Received: 15 March 2020 Accepted: 7 July 2020

Published online: 26 August 2020

\section{References}

1. Chilcot J, Spencer BW, Maple H, Mamode N (2014) Depression and kidney transplantation. Transplantation 97(7):717-721

2. Chen SF, Wang IJ, Lang HC (2016) Risk of major depression in patients with chronic renal failure on different treatment modalities: a matched-cohort and population-based study in Taiwan. Hemodial Int 20(1):98-105. https:// doi.org/10.1111/hdi.12334 Epub 2015 Jul 14

3. Szeifert L, Molnar MZ, Ambrus C, Koczy AB, Kovacs AZ, Vamos EP et al (2010) Symptoms of depression in kidney transplant recipients: a crosssectional study. Am J Kidney Dis 55(1):132-140

4. Andrade SV, Sesso R, Diniz DH (2015) Hopelessness, suicide ideation, and depression in chronic kidney disease patients on hemodialysis or transplant recipients. J Bras Nefrol 37(1):55-63

5. Dew MA, Rosenberger EM, Myaskovsky L, DiMartini AF, DeVito Dabbs AJ, Posluszny DM, Steel J, Switzer GE, Shellmer DA, Greenhouse JB (2015) Depression and anxiety as risk factors for morbidity and mortality after organ transplantation: a systematic review and meta-analysis. Transplantation 100(5):988-1003

6. El Mahalawy Naglaa, Hatata Hisham A, El Meguid Marwa A, Moneim Dalia A El Din Mohamed H, Hamed Rabei Samah. (2017): Correlates of psychiatric morbidity in Egyptian renal transplant recipients Middle East Current Psychiatry: April - Volume 24 - Issue 2 - p 85-92.

7. Mori D, Gallacher P, Milne J (2000) Structural interview for renal transplantation (SIRT). Psychosomatics 41:5

8. First MB, Spitzer RL, William JB (1995) Structured clinical interview for DSMIV (SCID-I) research version. Biometrics Research Department. New York Psychiatric Institute, New York

9. El-Missiry A (2003): Homicide and psychiatric illness, MD thesis of Psychiatry, Ain Shams University under supervision of Soror F, Sadek A, Assad A and Fahy T.

10. Beck AT, Steer RA, Ball R, Ranieri W (1996) Comparison of Beck depression inventories -IA and -II in psychiatric outpatients. J Pers Assess 67(3):588-597

11. Ghareeb AG (2000): Cairo Angle Press. Manual of the Arabic BDI-II. International Federation or Renal Registries (2003): statistics link of International Federation or Renal Registries, http://www.ifrt.ner/.

12. Cull JG, Gill WS (1992) Suicide probability scale. Western Psychological Services, Los Angeles

13. Al-beheiry A. (2003): The Egyptian version of the suicide probability scale (SPS). Cairo Anglo Press

14. SPSS Inc. released (2003) SPSS Statistics for Windows, Version 12.0. SPSS Inc., Chicago, IL

15. International Federation of Renal Registries (2003): statistics link of International Federation of Renal Registration. http://www.ifrr.net/Accessed: 07/15/03.

16. Ali A, Hendawy A (2015) Renal transplantation in the Middle East: strengths, weakness, opportunities and threats (SWOT) Analysis. UrolNephrol J 2(2):28

17. Hamdy S (2010) The organ transplant debate in Egypt: a social anthropological analysis. Droit et Cultures 59(1):357-365

18. Shaheen FA (2009): Organ donation in the Middle East countries. Ethn Dis 19 (1 Suppl1): 16-17.

19. Matas AJ, Halbert RJ, Barr ML, Helderman JH, Hricik DE, Pirsch JD, Schenkel FA, Siegal BR, Liu H, Ferguson RM (2002) Live satisfaction and adverse effects in renal transplant recipients: a longitudinal analysis. Clin Transplant 16(2):113-121

20. Cameron Jl, Whiteside C, Katz J, Devins GM (2000) Differences in quality of life across renal replacement therapies: a meta-analytic comparison. Am J Kidney Dis 35(4):629-637

21. Vásquez V, Novarro N, Valdés RA, Britton GB (2013) Factors associated to depression in renal transplant recipients in Panama. Indian J Psychiatry 55(3):273-278

22. Lin X, Lin J, Liu H, Teng S, Zhang W (2016) Depressive symptoms and associated factors among renal-transplant recipients in China. International Journal of Nursing Sciences 3:347-353

23. Babikir GK, Idris M, Hamad IA, Gadour M (2010) Psychological disorders and quality of life among Sudanese dialysis patients and renal transplant recipients. Sudan JMS 5:29-34 
24. Arapaslan B, Soykan A (2004) Soykan C and Kumbasar H (2004): Crosssectional assessment of psychiatric disorders in renal transplantation patients in Turkey: a preliminary study. Transplant Proc. 36(5):1419-1421

25. Anvar-Abnavi M, Bazargani Z (2010) Prevalence of anxiety and depression in Iranian kidney transplant recipients. Neurosciences (Riyadh) 15(4):254-257

26. Tsunoda T, Yamashita R, Kojima Y, Takahara S (2010) Risk factors for depression after kidney transplantation. Transplant Proc 42(5):1697-1681

27. Rocha G, Poli de Figueiredo CE, d'Avila D, Saitovitch D (2001) Depressive symptoms and kidney transplant outcome. Transplant Proc 33(7-8):3424

28. Novak M, Molnar MZ, Szeifert L, Kovacs AZ, Vamos EP, Zoller R, Keszei A, Mucsi I (2010) Depressive symptoms and mortality in patients after kidney transplantation: a prospective prevalent cohort study. Psychosom Med 72:527

29. Zelle DM, Dorland HF, Rosmalen JGM, Corpeleijn E, Gans ROB, van der Heide H, Jaap J, van Son WJ, Navis G, Bakker SJL (2012) Impact of depression on long-term outcome after renal transplantation: a prospective cohort study. Transplantation 94(10):1033-1040

30. Griva K, Davenport A, Harrison M, Newman S (2010) An evaluation of illness, treatment perceptions, and depression in hospital- vs. home-based dialysis modalities. J Psychosom Res 69:-363

31. Butler JA, Peveler RC, Roderick P, Smith PW, Horne R, Mason JC (2004) Modifiable risk factors for non-adherence to immunosuppressants in renal transplant recipients: a cross-sectional study. Nephrol Dial Transplant 19(12): 3144-3149 Epub 2004 Oct 12

32. Kurella M, Kimmel PL, Young BS, Chertow GM (2005) Suicide in the United States end-stage renal disease program. J Am Soc Nephrol 16(3):774-781 Epub 2005 Jan 19

33. Stanfill A, Hathaway D, Bloodworth R, Cashion A (2016) A prospective study of depression and weight change after kidney transplant. Prog Transplant 26(1):70-74

34. Akman B, Ozdemir FN, Sezer S, Miçozkadioglu H, Haberal M (2004) Depression levels before and after renal transplantation. Transplantation Proceedings. 36(1):111-113

35. Alavi NM, Aliakbarzadeh Z, Sharifi K (2009) Depression, anxiety, activities of daily living, and quality of life scores in patients undergoing renal replacement therapies. Transplantation Proceedings 41:3693-3696

36. Sağduyu A, Sentürk VH, Sezer S, Emiroğlu R, Ozel S (2006) Psychiatric problems, life quality and compliance in patients treated with haemodialysis and renal transplantation. Turk Psikiyatri Derg; Spring 17(1):22-31

37. Zarifian A (2006) Symptom occurrence, symptom distress, and quality of life in renal transplant recipients. Nephrol Nurs J 6:33

38. McGee RE, Thompson NJ (2015) Unemployment and depression among emerging adults in 12 States, behavioral risk factor surveillance system, 2010. Prev Chronic Dis 12:140451

39. Ojo AO, Hanson JA, Wolfe RA, Leichtman AB, Agodoa LY, Port FK (2000) Longterm survival in renal transplant recipients with graft function. Kidney Int. 57:307-313

40. Veater NL, Linda East $L$ (2016) Exploring depression amongst kidney transplant recipients: a literature review. J Renal Care 42(3):172-184

41. Leigh H, Strettzer J (2014) Handbook of consultation and Liasion psychiatry. Ren Kidney Transplant (Springer) 28:P410

\section{Publisher's Note}

Springer Nature remains neutral with regard to jurisdictional claims in published maps and institutional affiliations.

\section{Submit your manuscript to a SpringerOpen ${ }^{\circ}$ journal and benefit from:}

- Convenient online submission

- Rigorous peer review

- Open access: articles freely available online

- High visibility within the field

- Retaining the copyright to your article

Submit your next manuscript at $\boldsymbol{\nabla}$ springeropen.com 